\title{
The COVID-19 Response: Perspectives of Infectious Diseases and Clinical Microbiology Physicians in Turkey
}

\author{
Altan Gökgöz (iD, Ezgi Gülten² (D), Alpay Azap² (D), Serap Şimşek-Yavuz³ \\ 1 Department of Infectious Diseases and Clinical Microbiology, Eşrefpaşa Hospital, İzmir, Turkey \\ 2 Department of Infectious Diseases and Clinical Microbiology, Ankara University School of Medicine, Ankara, Turkey \\ 3 Department of Infectious Diseases and Clinical Microbiology, İstanbul University School of Medicine, İstanbul, Turkey
}

\begin{abstract}
Objective: We aimed to identify the needs and the roles of infectious diseases and clinical microbiology (IDCM) specialists during the COVID-19 pandemic.

Methods: We performed an electronic survey among the IDCM physicians who are members of the Turkish Society of Clinical Microbiology Infectious Diseases (Turkish SCMID, KLİMIK).

Results: In total 414 IDCM physicians responded to the survey with a response rate of $22.3 \%$. Sixty-five out of $81(80 \%)$ cities were represented with 300 health care facilities. The participants reported that COVID-19 emergency tasks including swabbing, triage and night shifts performed most commonly by IDCM physicians (92.7\%) followed by emergency medicine physicians (86.1\%) and daily tasks in inpatient clinics are most commonly performed by IDCM $(98 \%)$ physicians followed by chest diseases physicians $(78.1 \%)$. In $20 \%$ of health care facilities, the access to personal protective equipment and drugs was limited. The participants reported that from May to August 2020 at least 70 IDCM specialists have resigned because of work overload and exhaustion.

Conclusion: Successful management of a pandemic could only be possible by participation and harmony of all local and national task forces. Professional societies such as KLIMIK became more important after the experience of the pandemic.
\end{abstract}

Keywords: COVID-19, infectious diseases and clinical microbiology specialty, management

\section{INTRODUCTION}

I nfectious Diseases and Clinical Microbiology (IDCM) physicians have pivotal role in responding to the coronavirus disease 2019 (COVID-19) pandemic. Their involvement 1 ranges from managing cases and coordinating local responses to establishing timely and accurate diagnostic testing (1-3).

Managing a pandemic properly is the key element to minimalize the devastating effects in total. From this point of view, identifying the deficiencies as well as the requirements of each facility is essential to control the outbreak. Health care workers (HCWs)
Corresponding Author: Ezgi Cülten

\section{E-mail:}

ezgioztop@gmail.com

Received: December 20, 2020 Accepted: December 28, 2020 Published: December 31, 2020

\section{Suggested citation:}

Gökgöz A, Gülten E, Azap A, Simşek-Yavuz S. The COVID-19 Response: Perspectives of Infectious Diseases and Clinical Microbiology Physicians in Turkey. Infect Dis Clin Microbiol 2020; 3: 153-157.

DOI: $10.36519 / \mathrm{idcm} .2020 .0033$ 
of all stages are the most important defensive arms against local and global calamities such as COVID-19. The goal to achieve a sustained health care system could be feasible by defining and meeting the needs and expectancies of HCWs.

Therefore, as a task force of the Turkish Society of Clinical Microbiology and Infectious Diseases (KLİMIK), we performed a survey among IDCM physicians to describe the roles and needs of them in the COVID-19 pandemic.

\section{METHODS}

We designed an electronic survey to describe the role and needs of IDCM specialty during COVID-19 outbreak and obtain views of IDCM physicians. The survey was consisted of three parts: i) information related to the participants and their working facilities, ii) Managing COVID-19 outbreak at the facility iii) Major problems and limitations experienced by physicians during COVID-19 pandemic and their expectations.

The questionnaire was delivered to IDCM physicians via social media platforms of Turkish SCMID (KLIMIK). The survey was employed on 19-27 August, 2020.

Statistical analysis was performed by using SPSS v27.

\section{HIGHLIGHTS}

- Infectious diseases and clinical microbiology (IDCM) physicians have a pivotal role in the management of the COVID-19 pandemic.

- IDCM physicians were over-loaded and exhausted because of insufficient support of the administrators, thus from May to August 2020, at least 70 IDCM specialists have resigned.

- IDCM physicians stated that medicine and protective equipment for COVID-19 were accessible in $80 \%$ of healthcare settings.

- There were some limitations on accessing the drugs; however, these drugs did not have a significant impact on health.

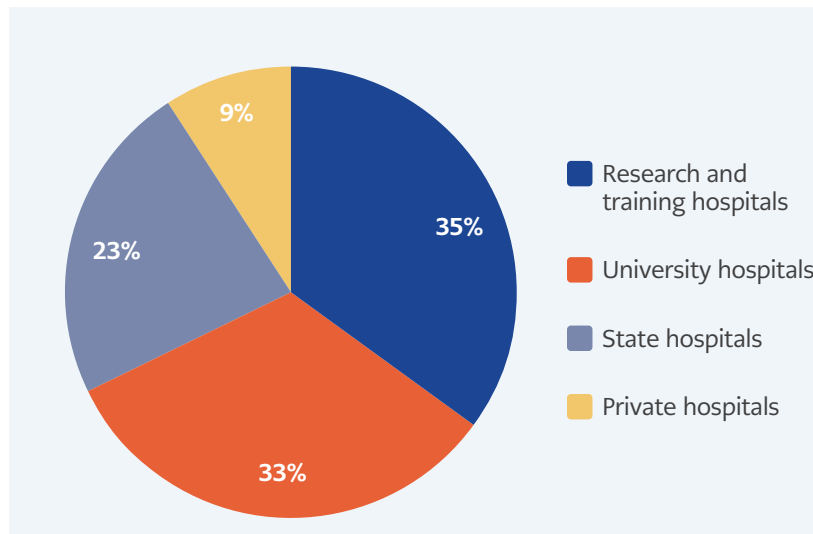

Figure 1. The distribution of the type of the health care centers

\section{RESULTS}

A total of 414 IDCM physicians responded to our survey, with a response rate of $22.3 \%$ (414/1854). Ninety-five $(22.9 \%)$ of 414 participants were academics (professor or associate professor), 211 (50.9\%) were specialists, and 95 (22.9\%) were trainees.

In geographic distribution, sixty-five out of 81 (80\%) cities were represented. The participants' facilities were in Marmara (149,36\%), Central Anatolia (72, 17.4\%), Aegean (59, 14.3\%), Mediterranean (55, 13.3\%), Southeast Anatolia (30, 7.2\%), Black Sea (26, $6.3 \%)$, and Eastern Anatolia region (23, 5.5\%).

The participants responded from 300 different health care centers. Of these, 105 (35\%) were research and training hospitals of the Turkish Ministry of Health, 99 (33\%) were university hospitals, 72 (23\%) were state hospitals, and $24(9 \%)$ were private hospitals (Figure 1). In 213 (71\%) of these centers, there were more than 500 patient beds. The other hospitals were relatively small with 101-500 ( $\mathrm{n}=57$, $19 \%)$ and 50-100 patient beds ( $\mathrm{n}=30,10 \%)$.

The participants were asked to report which physicians serve in emergency tasks and inpatient clinics. IDCM (92.7\%), emergency medicine (86.1\%), chest diseases (64.7\%), internal medicine (66.7\%), and ear-nose-throat (43.8\%) physicians were reported to be involved in COVID-19 emergency tasks including swabbing, triage, and night shifts (Figure 2). In terms of duties in inpatient clinics, 


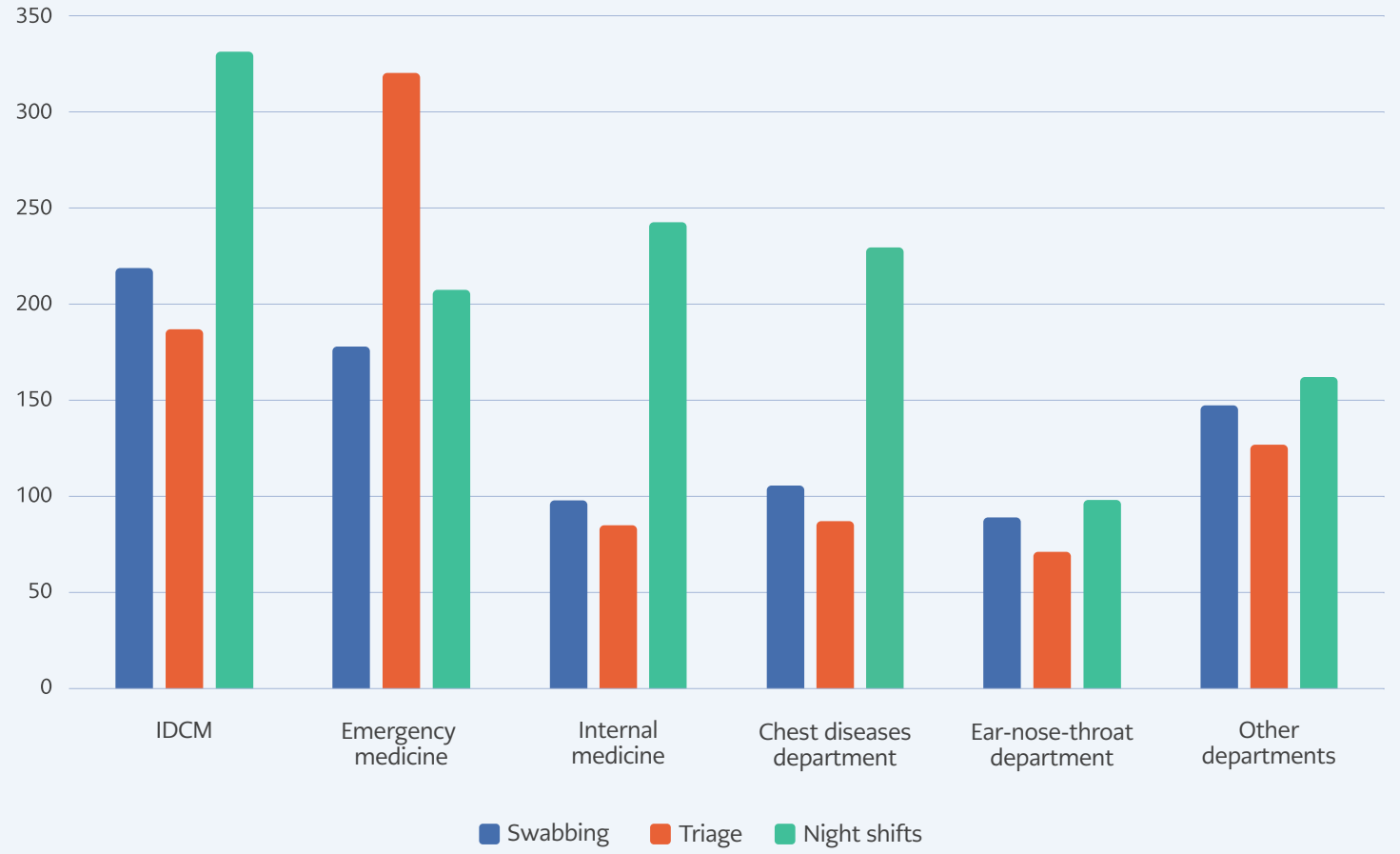

Figure 2. The role of departments in COVID-19 emergency services

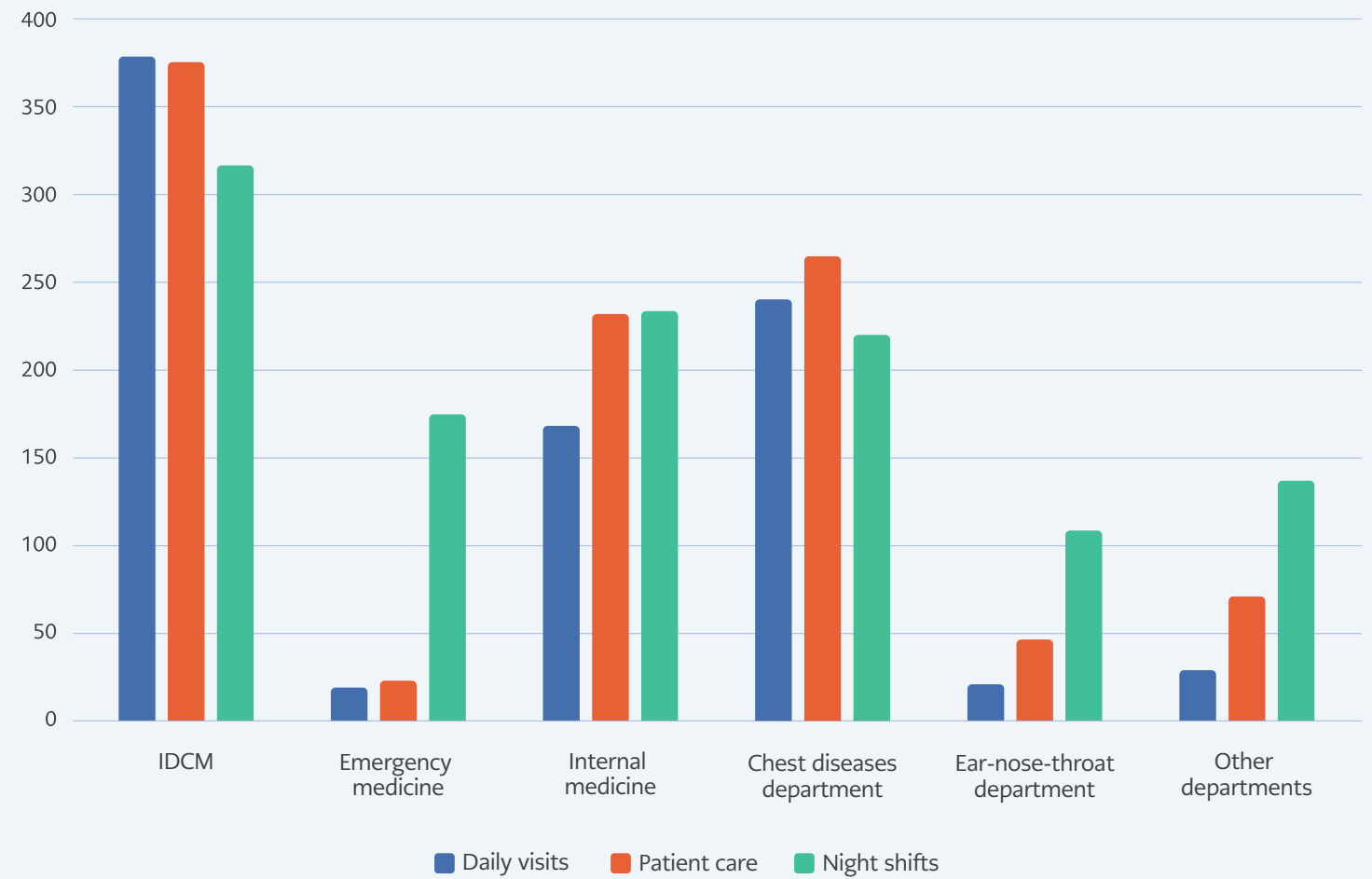

Figure 3. The role of departments in COVID-19 inpatient services 
IDCM (98\%), chest diseases (78.1\%) and internal medicine $(72.9 \%)$ physicians have taken on the responsibilities of daily visits, patient care and night shifts. In 173 (57.7\%) and 134 (44.7\%) facilities, other departments have also been sharing the role in emergency tasks and inpatient services, respectively (Figure 3).

Eighty-four (20.2\%) physicians declared that they had difficulty in obtaining some of the drugs, namely favipiravir, lopinavir/ritonavir and hydroxychloroquine, 80 (19.3\%), 25 (6\%), and $5(1.2 \%)$, respectively. Seventy-eight (18.8\%) attendees indicated the lack of personal protective equipment (PPEs) at their facilities. In detail, participants stated the shortage of FFP2 masks $(61,14.7 \%)$, surgi$\mathrm{cal} /$ medical facemasks (28, 6.8\%), disinfectants (24, $5.8 \%)$, helmets (18,4.3\%), gloves (15, 3.6\%) and goggles $(13,3.1 \%)$.

In total, 244 (59\%) participants reported their concerns about available beds for patients in either inpatient clinics or intensive care units. When compared with the interval between March 2020 and June 2020, it was observed that this problem became even more pronounced between July 2020 and August 2020 (24\% vs. 65\%).

At the facilities of 177 (42.7\%) participants, there were at least one IDCM physician infected with SARS-CoV-2. The most common problems which the physicians experienced during the COVID-19 outbreak were insufficient support of hospital administrators and colleagues from other departments, deficiencies in diagnosis and treatment tools, intense and tough working conditions (i.e., long working hours, oppressive protective equipment, lack of resting hours), and exhaustion. The participants reported that from May to August 2020, at least 70 IDCM specialists have resigned due to one or more of these issues.

\section{DISCUSSION}

Our findings showed that IDCM physicians are the leading HCWs in management of COVID-19 cases in many hospitals, followed by emergency medicine, chest diseases, internal medicine and ear-nosethroat physicians. In order to reduce their exhaus- tion, IDCM physicians expect health authorities and hospital administrators to assist role share.

Although none of the participants stated an insufficiency in the number of IDCM physicians, their long working hours with no break somewhat indicated the need for IDCM specialists.

Moreover, recent resignations and retirements of IDCM physicians urged taking steps to relieve exhaustion.

In the United States, a growing shortage of infectious disease (ID) physicians, and even fewer ID trained hospital epidemiologists were reported previously. The number of medical school graduates seeking a career in ID has consistently decreased over the last decade, with nearly $40 \%$ of ID training fellowships going unfilled (3). However, the pandemic has the potential to change this paradigm.

Infection control surveillance and organization was established in 2004 in Turkey. Infection control teams and committees (ICT) are working actively since 2004. Taking the leading role in ICT, IDCM physicians have been dealing with infection control measures in their daily routine. The pandemic added to the tasks of IDCM physicians in ICTs. Another responsibility of IDCM physicians is the control and organization of HCW vaccination programs in health care facilities. Although the compliance of the HCWs with vaccination was reported to be low even among ICT members in Turkey (4), mass vaccination programs against COVID-19 will be added to these responsibilities.

At the beginning of COVID-19 outbreak in Turkey, canceling or postponing elective medical/surgical procedures allowed the physicians to meet the requirements of patients who need to be followed in hospital settings (5). Nevertheless, accepting patients other than COVID-19 resulted in difficulties in finding available beds. This problem originated from reserving inadequate number of beds for COVID-19 patients rather than the absence of beds. Therefore, we suggest each facility to conduct a flexible plan-of-action by following actual local and national COVID-19 status. 
The results showed that, the shortage of drugs and PPEs does not pose a problem in most facilities. Nonetheless, health authorities and hospital administrators should ensure sufficient supplies for the worst-case scenarios.

There were several limitations to our study. The response rate was $22.3 \%$, but it should be increased, related to the society members' dedication. The questionnaire included the tasks they were involved with at their facilities without specifying the exact time spent on each task. This did not allow to determine the exact increase in workload. The burden of the pandemic was different in various regions of the country at the time of the survey. Our results may not be generalized due to local variabilities. Nevertheless, the study is still strong in representing various types of health care facilities as well as IDCM physicians at different stages of the profession.

\section{CONCLUSION}

Successful management of a pandemic could only be possible by participation and harmony of all local and national task forces. Turkish SCMID (KLiMIKK) is ready to cooperate with its $>2000$ registered members. Professional societies became more important after the experience of the pandemic.
Peer-review: Externally peer-reviewed

Author Contributions: Concept -ALL; Design - ALL; Supervision - ALL; Fundings - ALL; Materials - ALL; Data Collection and/or Processing - ALL; Analysis and/or Interpretation - ALL; Literature Review - ALL; Writer - ALL; Critical Reviews - ALL
Conflict of Interest: The authors have no conflict of interest to declare.

Financial Disclosure: The authors declared that this study has received no financial support

\section{REFERENCES}

1 Foley DA, Tippett E; Australasian Society for Infectious Diseases Clinical Research Network. COVID-19 response: the perspectives of infectious diseases physicians and clinical microbiologists. Med J Aust 2020; 213: 431-431.e1.

2 Bearman G, Pryor R, Vokes R, Cooper K, Doll M, Godbout EJ, et al. Reflections on the COVID-19 pandemic in the USA: will we be better prepared next time? Int J Infect Dis 2020; 96: 610-3.

3 Foley M, O'Neill I, O'Neill B, Humphreys H, Burns K, de Barra E, et al. From bench to bedside - development of an integrated COVID-19 patient flow management system. J Hosp Infect 2020; 106: 211-3.
4 Keske Ş, Mutters NT, Tsioutis C, Ergönül Ö; EUCIC influenza vaccination survey team. Influenza vaccination among infection control teams: A EUCIC survey prior to COVID 19 pandemic. Vaccine 2020; 38: 8357-61.

5 Cimen C, Keske Ş, Ergönül Ö. What is the 'new normal' in surgical procedures in the era of COVID-19? Clin Microbiol Infect 2020 Sep 30. doi: 10.1016/j.cmi.2020.09.038. [Epub ahead of print]. 